\title{
A Qualitative Investigation of Masculine Identity After Traumatic Brain Injury
}

MacQueen, Ruth ${ }^{1,2}$; Fisher, Paul ${ }^{1,3}$ and Williams, Deirdre ${ }^{1}$

${ }^{1}$ Norwich Medical School, University of East Anglia, Norwich, UK

${ }^{2}$ Cambridgeshire and Peterborough NHS Foundation Trust, Cambridge, UK

${ }^{3}$ Norfolk Community Health and Care NHS Trust, Norwich, UK

All correspondence should be directed to Dr Ruth MacQueen Co Dr Paul Fisher, Department of Clinical Psychology, Elizabeth Fry Building, University of East Anglia, Norwich, NR4 7PA.

E-mail: ruth.macqueen@ nhs.net

Word Count 8126

Declarations of interest: None. 


\section{A Qualitative Investigation of Masculine Identity After Traumatic Brain Injury}

Men are twice as likely as women to experience a traumatic brain injury (TBI) suggesting that aspects of masculine identity contribute to how people acquire their brain injuries. Research also suggests that masculine identity impacts on how people manage their health experiences. The current study aimed to explore the experience of masculine identity following TBI.

Individual interviews were conducted with 10 men aged 21-67 years who had experienced a TBI. All were living in the community. Interpretative phenomenological analysis was used to consider lived experiences and to explore the meaning of the TBI experience in relation to masculine identity.

Three superordinate themes emerged from the analysis: doing life and relationships differently, self-perceptions and the perceived view of others and managing the impact as a man. These themes are considered in relation to how participant's experiences interacted with dominant social ideals of masculine identity.

The findings highlighted how masculine identity may be a valuable aspect of self in considering threats to and reconstruction of self-identity after TBI. Aspects of gender identity should be considered in order to promote engagement, support adjustment and achieve meaningful outcomes in rehabilitation.

Keywords: traumatic brain injury, masculine identity, neurorehabilitation, adjustment. 


\section{Introduction}

\section{Identity and Traumatic Brain Injury}

Prevalence of traumatic brain injury (TBI) in men is two times higher than in women (Key Facts and Statistics, Headway, 2014). This has been attributed in part to socialisation of masculine ideals which encourage risk-taking behaviour in men (Javouhey, Guerin, \& Chiron, 2006). Men also sustain more injuries playing high impact sports (Hollis et al., 2009) and are more likely to be in occupations, such as military employment, which increase the risk of experiencing TBI (Meyers, 2012).

Socially constructed ideals about what it means to be a man have been identified as including providing for and protecting others, physical strength, emotional toughness, selfreliance, competitiveness, risk taking, aggression and power (Addis \& Mahalik, 2003; Connell, 2005). Men who have had a serious injury may not continue to enact masculinity in the ways in which they did prior to injury and societal discourses about brain injury or disability have been considered to conflict with these dominant ideals of masculinity (Wilson Shuttleworth, Wedgwood \& Parmenter, 2012). Given the potential cognitive, emotional, behavioural, social and physical impact of TBI, the day-to-day lived experience, as well as roles and relationships, can be altered (Tyerman, 2009) and disrupt aspects of self, including masculine identity.

Theories aiming to explain self-identity highlight that social context influences identity. Social identity theory (Tajfel \& Turner, 1979; Jetten, Haslam \& Haslam, 2012) suggests that social identity is created through self-categorisation; considering the self in relation to similarities or difference with others, and social comparison; evaluating our own attributes favorably or unfavorably compared to others. Following TBI, the perception of self in the processes of self-categorisation and self-comparison may be challenged and result in 
self-discrepancies between the past, present and future self, in which the present self tends to be viewed negatively (Carrol \& Coetzer, 2011). In addition, neuropsychological processes which underpin self-identity such as autobiographical memory (Conway and Pleydell-Pearce, 2000) and emotion processing (LeDoux, 2000) may be disrupted following TBI.

Thomas, Levack, and Taylor (2014) drew on existing theories and developed a framework which aimed to explain the process of change in identity following TBI. The framework outlines a cyclical and dynamic process and suggests that change can occur on three levels including component parts (such as egocentric self and sociocentric self), integral processes (such as expression through meaningful occupation and narratives) and whole system disruption. It is suggested that this individualistic process is driven by "self-reflective meaning making" (p1037) giving a purpose and direction in life, providing motivation and goals for future behavior.

Research has identified that the experience of TBI includes narratives of positive growth including identity expansion through personal goals, looking to the future, a desire to give something back and a new sense of self (Freeman, Adams, \& Ashworth, 2014; Muenchberger, Kendall, \& Neal, 2008). Given these findings, it is important to understand identity after TBI, not only in relation to the difficulties in adjusting to changes, but also in relation to the factors which promote positive adjustment.

\section{Masculine identity and adjustment after TBI}

Research suggests that masculine identity can impact on how men manage the experience of illness. Men's experience of adjustment has been researched in various health conditions including prostate cancer (Ervik \& Asplund, 2012), spinal cord injury (Good et al., 2008) and cardiac health (Robertson, Sheikh, \& Moore, 2010). Literature has highlighted that adherence to masculine ideals can in some ways be harmful to one's health. 
For example, the idea that illness, or asking for help, is a sign of weakness can be a barrier to help-seeking behaviour (Courtenay, 2000; Galdas, Cheater, \& Marshall, 2005). However, there is evidence that some masculine ideals, such as a desire for success, encourage helpseeking or health promoting behaviour. For example, where men perceive the threat to their health as compromising their masculinity, help-seeking may be a way of preserving masculine identity. Therefore, masculine identity can aid men's ability to overcome adversity (Good et al., 2006).

Masculine identity has been found to have an impact on the process of adjustment after TBI where individuals integrate their new lived experiences to their identity and consequently reconstruct their sense of self (Lennon et al., 2014). The impact of gender on the experience of TBI and rehabilitation was first considered using qualitative research by Gutman and Napier-Klemic (1996). They interviewed two men and two women, exploring changes in perceived masculinity or femininity, intimate relationships, gender roles and engagement in activities which support gender roles. The research suggested that the men tended to rely more on gender-specific activities pre and post injury to define their gender role. The researchers suggested that, for men, failure to meet pre-injury standards resulted in feeling like "less of a man" (p. 542). Given the small sample size and that all participants lived in supported accommodation, conclusions from this study are limited.

Jones and Curtin (2011) focus on experiences of changed domestic roles such as caring and household duties and consider this in relation to reformulation of masculine identity. Participants described either rejecting the reformulation of their masculinity, accepting it for the sake of others or personally valuing their changed masculinity. The findings illustrated the significance of the change of role from breadwinner to a carer or domestic role and how men's perceptions of these changes related to their perceptions of 
quality of life. However, this research did not explicitly investigate gender in relation to changes in roles and therefore the interpretations should be treated with caution.

Men's lived experiences of perceived changes in personal and social identity in relation to their social world has been considered by Freeman, Adams, and Ashworth (2014). Themes identified included 'abnormality', 'the hidden nature of brain injury,' 'others treat me different' and 'the old me- new me,' all of which were suggested to contribute to emotional threats including loss of self, blame, guilt, shame and loss of pride. Participants also talked about how acceptance was related to the perception that others treated them the same as prior to their injury. This appeared to lead to positive growth as participants talked about moving on and making the most of life. However, this research focused on social and emotional experiences, rather than directly considering the phenomenology of masculine identity. A more direct exploration of the internal experience of men may therefore further the understanding of how therapeutic approaches can consider masculine identity in supporting adjustment following TBI. This current study aimed to gain an in-depth understanding of the lived experience of masculine identity for individuals following TBI.

\section{Method}

Interpretative Phenomenological Analysis (IPA) (Smith, 1996) was chosen as it allows people to share their experiences and the sense they make of them within their own social and cultural context (Biggerstaff \& Thompson, 2008; Larkin, Watts, \& Clifton, 2006).

Epistemologically this study situated itself within a contextual constructivist position (Smith, Flowers \& Larkin, 2009), meaning that all knowledge is context specific. The experience of a person therefore becomes meaningful through their interaction with the world. The person is situated within their own context and therefore history, culture and environment contribute to how a person makes sense of their experiences. 
Qualitative research acknowledges that the researcher's interpretation is also influenced by their own experiences, including their experiences with the data gathered (Shinebourne, 2011). Given this, a reflexive approach was used throughout the research. Ethical approval was obtained from the Research Ethics Committee of the National Health Service Research Authority.

\section{Participants}

Ten men, all of white British ethnicity aged between 21 and 67 years were recruited from an NHS community rehabilitation service. Participants were required to have insight into their experiences and to communicate in English. Having a communication difficulty did not exclude individuals as support around expressive language difficulties could be provided. Table one provides an overview of the participants. Pseudonyms have been used throughout. [Table 1 near here].

After a briefing from the first author, clinicians identified potential participants whom they approached with the Participant Information Sheet. If the potential participant was interested in the research, written consented was obtained for the first author to contact them, provide further information and arrange an interview.

\section{Data collection}

Participants were interviewed individually either at the rehabilitation service $(n=5)$ or in their homes $(n=5)$, depending on their preference. Interview length ranged from 52 to 71 minutes. The aim of the interview was for participants to be able to communicate their narratives, thoughts and feelings about their experiences in order to obtain rich interview data. The interview was directed by a topic guide that was developed by considering the themes which were relevant to the research question, including the impact of TBI, masculine 
identity, cultural and social roles, as well as experiences of rehabilitation. Open ended questions were asked such as, "Can you tell me about any times when you particularly felt TBI impacted your identity as a man?”

\section{Analysis}

Data analysis adhered to the guidelines described by Smith et al. (2009 p.79). The first author transcribed the interviews and read the transcripts several times in order to become familiar with and immersed in the data (Rodham, Fox, \& Doran, 2015). Detailed comments were then made including that of the first authors own interpretations of the underlying meaning of what was being said. This led to each individual transcript having between 40 and 100 emergent themes. These emergent themes were then clustered and given a descriptive label or master theme. The final stage of analysis identified patterns in master themes across participants. Eight master themes were identified and then grouped into three superordinate themes. The three superordinate themes were present in all of the participant interviews. Each theme was again reviewed in relation to the transcripts to ensure that the interpretation remained grounded in the data. Each stage of the analysis was reviewed with the second author and the themes were verified in collaboration with the third author.

\section{Quality}

Smith (2011) outlines features of high quality IPA research and develops guidelines for evaluating quality in IPA. To adhere to these criteria, a team approach was used throughout as a way of improving the quality of the research. This included the authors regularly discussing key decisions made at different stages of the research process, and also adherence to The Consolidated Criteria for Reporting Qualitative Research (Tong, Sainsbury, $\&$ Craig, 2007). The use of a reflective diary and reflexivity throughout the research process 
contributed to the quality of the research. In addition, a detailed record of the analysis process was mapped so that the data could be traced throughout (Yardley, 2008).

\section{Results}

Three superordinate themes emerged from the analysis: doing life and relationships differently, self-perceptions and the perceived view of others, and managing the impact of TBI as a man. Each of the three superordinate themes were present in all participant interviews and verbatim quotes are presented below. A detailed hierarchical representation of the organisation of themes can be found in Figure 1. [Figure 1 near here]

\section{Doing Life and Relationships Differently}

All participants talked about how the injury had affected different aspects of their lives. The impact of the injury on activity resulted in changes in roles and relationships within family, work and social groups.

\section{Loss of individual agency and independence.}

Participants talked about experiences of loss of independence and the loss of the freedom to make their own choices.

A man should be in charge and organised and know what they're doing but now I have to rely on a bit of pen and paper. ... It makes you feel, again, it makes you feel like a child, it makes you feel like you can't control your own life because you're having to rely on looking at something to remind you. Chris

Similarly, Jake, Smith and Gordon also highlighted different ways in which they no longer felt that their mind or body was co-operating with how they wished to live their lives. 
Discomfort with reliance on others was also expressed and some participants described feeling in a very childlike position.

I just don't feel adequate as a man in any way now. It just feels always have to be babied or watched and you know ... I just can't take the responsibility that I used to. Gordon

Jake talked about how his initial reluctance to seek help from professionals was linked to his identity as a man:

(Rejecting help) was like so I felt like a man so I felt like I was still in control... Accepting help is horrible, cause I knew by accepting the help, other people would have to drop things to then help me do you know what I mean, so accepting the help, was sort of accepting defeat, I was accepting the fact that I need help.

Many of the participants talked about loss of control over their finances and major life decisions as a significant loss to them.

I'm not allowed to control my own money. Oh Christ, that's a hugely emasculating thing actually! John

\section{Roles and relationships.}

All of the participants talked about how the injury had an impact on their roles and relationships in their lives. Nine participants indicated that they felt that either they were a burden to their partners or that at times they experienced a degree of insecurity when comparing themselves unfavourably to other men because of how the effects of TBI might 
impact on a partner. For example, Simon talked about how the division of household labour has changed:

I can't cut the (lawn), so my wife does. Putting out the bins my wife does. And that saddens me as (it's something a) husband should do.

All four men who were fathers of younger children talked about the impact on their role as a father, often in relation to roles as protector and provider.

I wasn't doing anything that I felt contributed to my family. I felt like an embarrassment, I felt that my kids, or my kid at that time would grow up to be so ashamed like when people at school say "Oh, what does your daddy do?" I mean I remember (my daughter) asking me for the first time "Daddy, what do you do for a job?" I was like e"Erm"; I didn’t know how to answer it. Erm, yeah, I didn't really, I mean what was my purpose, my existence revolved around medical appointments, medical assessments and being a burden to everyone around me. It was horrible. I didn't provide anything for anyone. Yeah there was a roof over our heads and all the rest of it, but I wasn't the breadwinner in any respect. John

Both George and Nigel talked about how the impact of their injury on their emotional regulation had directly affected their role as a father.

I know I've done wrong by how I've reacted, but I just do it anyway you know. ..., I just sorta haven't got the patience I used to have basically....It's upsetting, because I've upset my daughter and I've seen her get upset over it. George. 
Changes in work roles and relationships were also identified by participants in relation to their identity as a man. This appeared to overlap with the role of provider within the family. There was a sense of status as a man being threatened at times within the work context.

I said to (wife) I'm a bit worried now that I get redeployed cause I can't do night shifts, they might redeploy me to a job or whatever and I don't wanna lose the respect that I've sort of built up the last 20 odd years, you know working my way up and because of someone ran me over I'm back down there again. Nigel

Luke and Peter, in their early 20's, were the youngest participants. Their interviews suggested that they both identified with peer group expectations about how they should be living their lives and they appeared to feel isolated from their pre-injury peer groups.

Like, where I used to work, Friday night would be going down the pub for a few pints, then Saturday would be going into town and getting a bit more than a few pints but yeah that's a bit rubbish cause now you're sort of at home, sat in, with not really much to do. ... You think like I'm (age), I should be out making the most of it, whereas I'm just sat here watching TV, it's not great. Peter

\section{Self-perceptions and the Perceived View of Others}

Participants talked about how they felt their own lived experience was different from how others saw them. This often related to activities which they felt they should be doing as a man but were not. When this was identified either by themselves, or they believed that others 
perceived them not to be meeting the expectations of a man, participants experienced shame and embarrassment.

\section{The invisible nature of the injury as both protective and threatening to masculine identity.}

The invisible nature of brain injury was considered in comparison to a visible physical injury or disability. This appeared to result in both positive and negative experiences in relation to masculine identity.

Nigel talked about how the outer shell of normality hides his internal experience: Cause I mean a lot of it, it's difficult for a lot of people, cause they look at me "Oh you look fine" "You look no different." You look like, you know (laughs) you look you know just the same and but you know, that's just the outer shell, they can't see obviously what's in there (gestures to head).

The invisibility of the injury for Nigel and the ability for the "outer shell" to appear the same may suggest that he felt others did not understand his experience, or the effects of his injury. However, this may also have been a protective shell in some ways as he later talked about how he prefers to keep internal emotions to himself.

Similarly, George indicated that he preferred his internal experience to be private: Cause you don't obviously go and tell everyone down there (the local pub) what's going on in your head you know, well I don't anyway.

\section{Concern about being judged as less of a man.}

Participants expressed concern that they would be judged negatively as a man by others due to the injury. Sometimes this was based on actual experiences of stigma of 
negative stereotypes about head injury, while at other times, the concern appeared to be in anticipation of these.

It do make you think, like would that person actually look at me any different, just because I had a serious car accident and a brain injury? Like would they sit there and think, for instance, I don't want my daughter to be with this person. Luke

Peter considered how other people may view him as not living up to physical expectations of being a man:

I'm thinking everybody (is) looking at me thinking "Why is he not doing that" sort of thing....You see again, that's (lifting weights) like a bit of a masculinity thing as well, like we go to the gym and we do weights in front of mirrors and I'm doing like $3 \mathrm{~kg}$ weights cause of my left arm's pretty crap and that's all I can really lift which is a bit rubbish really. ... When I went with the physio I'd do it cause I'd happy got an excuse then to do it, but on me own I don't wanna sit there and do $3 \mathrm{~kg}$ weights, $3 \mathrm{~kg}$ weights cause it just looks rubbish sort of thing.

Gordon appeared to have different self-evaluations in relation to societal expectations of a man depending on the group context he was in.

I feel more manly there (in the brain injury social group), ...I feel more myself there because I can let myself, erm, just be myself, who I am. But on the outside world (I'm) trying to act as though...I suppose I put a front on in the real world as a man my age. 


\section{Shame and loss of self-confidence.}

Participants expressed that they experienced shame and loss of self-confidence which was related to how they perceived themselves and how they thought that others viewed them as a man. John describes his experience as "humiliating" and highlights some of the day-today lived experiences which contributed to this:

(Wife) had to help me shower for a couple of weeks after the accident and I mean, like, how is she going to find me attractive and sexy (he laughs) if she's got to basically wipe my arse for me? ....I doubt (wife) could have fancied me or found me attractive because she was my carer, and I certainly felt too ashamed to even try that (sex). John

A change in physical appearance and ability was also identified as having a diminishing effect on self-esteem for participants.

When I was in hospital I lost 3 stone and I used to like working out before and I used to be at work and playing football, so I was very active. My job was very active so I was enjoying life as such. And then I'm 3 stones lighter and just not having no confidence whatsoever. Luke

Participants experienced feelings of loss, shame, embarrassment and inadequacy when comparing themselves to other men who did not have a TBI.

That night it was embarrassing because I just, I couldn't stop you see, and I felt bad because I let her down, must have made a laughing stock of myself and I just couldn't cope and I just, couldn't cope. Then that makes you think there's other people our age, and their husbands, boyfriends they're 
all fine, they get on with it and that puts me back, that sets me back socially. Gordon

\section{Not feeling safe, feeling vulnerable.}

Participants shared that having the injury meant that they tended to behave in a more cautious way and that they were more aware of risk. This appeared to be related to their own sense of how further injury may potentially affect them or cause death.

(Being punched by someone), that kind of brought home as well how frail, I suppose, I feel which is again emasculating. John

I know I could look after myself if you know what I mean, as in with fists, where now I've got a broken finger, I can't clench my fist and I haven't got the confidence so much to argue back either. George

\section{Managing the Impact of TBI as a Man}

Participants talked about different ways by which they managed the impact of living with a TBI in relation to their identity as a man. For some, the impact had resulted in reevaluating their life and their values, and they felt that the impact of the injury had had some positive influences.

\section{Coping with adjustments.}

Participants highlighted that characteristics such as strength and resilience had been part of their recovery following injury. These ideals appeared to related to participant's identity as a man. 
Like a man should be someone who's powerful, someone that can't be knocked down, can't be brought down by what's happened, make the bright side of anything. Like someone that can support people, show people that there is like there's no point in giving up and that, cause at times I felt like giving up, can't be bothered with it anymore cause I'd get stressed and depressed about it, but there aint no point in being like that, I've got the rest of my life to live....it (having help) doesn't make you any less of a man, if anything it makes you stronger cause you learn new things. Jake

Similarly, Luke appeared to have reformulated the use of compensatory strategies as a means of promoting independence, rather than being a sign of reliance.

It's not too bad actually (using memory aids such as lists). In a way (I) prefer it cause at least then I'm not 'Oh should have done this, should have got this today.' Luke

Participants discussed how they coped with adjustments through adapting activities, compensating or thinking about things differently.

I can do other stuff to make up for it. So yeah. It's you can see it's still raw, upsetting to think of stuff I can't do, but then think of ways I can make up for it....(I'm) finding other ways of trying to make up for the way I am. So I erm grow a lot of flowers or veg or fruit, so it tries to outweigh (not cutting) the grass. Simon

I call it a siesta because it makes it feel cool and continental. When it's referred to as a nap, I feel like a baby.... It took (wife) basically 2 years to 
argue with me to get me to nap, cause if I don't recharge my batteries I'm no use as a father in the evenings which is even more humiliating. So me having an hours rest before (child) comes home from school, I can contribute as a parent. John

Being able to maintain some pre-injury activities appeared to be protective for participants identity as a man after injury.

I still do eh, you know I still do the blokey things, you know, go down the pub, meet friends, I don't drink much now cause I have to be careful with the brain injury and alcohol and stuff so you know I still do that, go to the football. Nigel

\section{Re-evaluating life and values.}

Participants reported that they felt that they had been given a second chance and often considered how much more severe the impact of their injury could have been. However, explicitly referring to feeling lucky appeared to contrast with the reality of difficulties in dayto-day life.

Apparently, I should have been dead or in a wheelchair for the rest of my

life. So its's weird cause I feel like the luckiest unlucky person. John

Participants reflected on how their experiences following injury had contributed to a change in the way they fulfilled roles as a man. For example, both John and Simon discussed how they had found values in new community roles. George talked about how before his injury he had prioritised work and providing material things for his family and John described himself as having been "a man about town." However, for them both, the injury appeared to 
have contributed to a change in behaviour which meant expressing values as a man in a different way.

I've joined the PA (Parents Association) at my (child's) school, because I've got the time to do it and I want to contribute. John

I've got no idea what I'm gonna do but at least I'll spend some more time with my kids. You know so at least, after having this happen I think family's a very big thing for you. You know. It's all very nice to have money, which I have a bit of money, done all right for myself, but it puts a different perspective to what's important, and in my eyes, family is. George

\section{Discussion}

The findings of the current study demonstrate that when participants felt they did not meet pre-injury standards, they experienced a conflict or discrepancy between past, present and future identity as a man. Discrepancies were identified in ideals such as self-reliance, autonomy, physical appearance, being decisive and in control. This appeared to relate to a sense of discrepancy within roles and positions within relationships, family, work and social contexts.

The men in the study talked about how the injury had changed the ways in which they carried out relational and family roles. This included no longer being able to be responsible to care for children, not fulfilling the role of a provider and not being able to cope with a busy family environment. In addition, difficulties in managing emotional responses and not being able to participate in shared leisure activities resulted in participants experiencing a 
discrepancy between roles and lived experience. The need for someone to supervise and remind them about daily activities conflicted with masculine ideals about independence, personal control and self-reliance. The change in activity and loss of the associated identity which was reinforced by that activity, consequently impacted on affiliative identities.

These findings also support existing literature which has suggested that being a father who has a brain injury has additional challenges (Morriss, Wright, Smith, Roser, \& Kendall, 2013). However, for parents, this role also appeared to provide a purpose and motivation to adapt in order to feel more able to fulfil their role as a father. Therefore, within rehabilitation this role should be included within assessment and intervention and it may be that aspects of this need to be re-considered as families change over time.

Activities which participants talked about differed in relation to the contexts of the individuals. For example, both Luke and Peter, the youngest participants, identified that they were not engaging in activities such as 'going out' at the weekend with peers, whereas older participants focused more on relationships and parenting. This supports Thomas et al.'s (2014) model which states that engaging in activities assumes a central role, both as a threat to self-identity, through loss or modification, and also in the reconstruction of self-identity. When participants felt that they were able to participate in age related gender activities, and maintain friendships or social groups, this appeared to be protective of aspects of their social identity. This continuation of pre-existing social connectedness through life transitions has been evidenced as being protective of wellbeing (Haslam et al., 2008). It may be understood in relation to the framework outlined by Thomas et al. (2014) as facilitating a continuation of aspects of sociocentric identity or that their experience of personhood in interactions has been maintained (Yeates, Gracey, \& Mcgrath, 2008).

The invisibility of the injury was considered by some to be protective of certain aspects of masculine identity, as participants talked about how they preferred to keep things 
private rather than share emotions in order to protect themselves. It may be that the invisibility also promoted a continuation of pre-injury social identity. This resonates with the findings of Nochi (1998) and Freeman et al. (2014), where participants identified that they were selective about the parts of themselves which they showed to others in order to appear 'normal.' For men, particularly those who identify with culturally dominant ideals of masculinity, this may be particularly important as a way of "saving face" or status seeking (Kingerlee, 2012, p. 7) rather than expressing emotion, difficulties or weaknesses to others. However, this may maintain a sense that the self is not acceptable and may result in avoidance of social participation. In addition, this may be a barrier to seeking appropriate support and having a negative impact on wellbeing (Kingerlee, 2012; Good et al., 2006).

In the current study an explicit reference to embarrassment or shame was present in half of the interviews. This contrasts with the results of Freeman et al. (2014) who highlighted that shame was only explicitly cited by two men out of nine in their study. Similarly, Gutman and Napier-Klemic (1996) identified that men talked about their activities with little expression of feeling. The prominence of shame in the findings of the current study may reflect the direct questioning about the meaning of experiences, as shameful emotions appeared to be associated with perceived devaluation of their identity as a man.

The analysis highlighted that the men made adaptations to activities, or found new activities which were in line with their values. For example, for Simon growing vegetables was a different way of providing for the family. Similarly, as he could not play football, he took his son to archery as this was something they could do together. These examples may be understood as ways in which Simon reformulated masculine identity. The ways by which he expressed masculine ideals, such as providing, were adapted given the resources available within his own context (Gerschick, 2000). Similarly, new roles within the community may enable a man to enact values through meaningful occupation (Jones \&Curtin, 2011). 
The drive to demonstrate abilities to self and to others appeared to arise from a sense of threat to masculine identity, but also appeared to provide motivation for participants to explore new ways of expressing masculine identities and perhaps influence post traumatic growth. For example, participants appeared to reformulate their behaviour, such as helpseeking or adopting compensatory strategies, as a demonstration of strength, taking control, or "regaining manliness" (John). Being able to reformulate their behaviour may also be influenced by adherence to dominant masculine ideals such as higher success, power and competition as this is associated with the perception of fewer barriers to community functioning (Hutchinson, \& Kleiber, 2000; Good et al., 2006).

\section{Limitations}

The findings represent a self-selecting group of participants who may have been more willing and able to communicate the sense-making of their experiences, and are therefore not representative of all men who have experienced a TBI. The participants had relatively lower educational levels compared to other similar research (Freeman et al., 2014) therefore this research broadens the representation of a range of backgrounds within the literature.

However, due to the population recruited, this study did not consider factors such as diversity in ethnicity, race or sexuality, which may also impact on the meaning of masculine identity in the context of experiencing a disability (Shakespeare, 1999).

Given the importance in IPA of privileging the individual's perspective of their own lived experience, additional demographic data which is commonly presented in brain injury literature was not collected. The lack of accurate medical information in this study means that it has not been possible to consider the relationship between experience and the type or severity of TBI. 
The interviewer was female and reflections on how this influenced her initial perceptions, the data collection and analysis were regularly undertaken. For example, during data collection it was noted that men apologised for swearing, and it may be that gender impacted on the speech content used to describe experiences. In addition, during analysis it was noted that only two participants talked directly about sexual experiences, a topic which had been expected to be of importance. It may be that men felt they could not talk about this with a female interviewer, and that this aspect of the lived experience is lacking in richness in the current study.

\section{Implications for Future Research}

This study highlighted that ideals about masculine identity, such as the necessity to carry on, be strong, and be resilient, appeared to be helpful for some participants in adapting to the impact of their injury and finding positive activities. Further research could explore how narratives of masculine identity may promote post traumatic-growth, wellbeing and adjustment after TBI. In addition, the application of recovery-focused approaches, such as Narrative Enhanced Cognitive Therapy (Roe et al. 2013) and Acceptance and Commitment Therapy in brain injury (Kangas \& McDonald, 2011), could be further researched. These approaches target self-stigma and could be applied in relation to loss of agency, shame and inadequacy as a man. In addition, these approaches may encourage flexibility in narratives and behaviour relating to masculine identity through consideration of values.

The current findings suggest that exercise and physical ability contributed to masculine identity and supports evidence from existing literature which suggests that exercise can have a positive impact on psychological wellbeing following TBI (Wise, Hoffman, Powell, Bombardier \& Bell, 2012). Further research could explore the use of interventions which encourage exercise as an activity to promote emotional adjustment and positive self- 
identity. Further consideration of prominent findings from the current research, such as the role of being a father and the experience of shame, could also be investigated. Existing data sources such as published narratives, blogs and biographies could be used to provide additional insight into lived experience following TBI.

Existing literature suggests that there is a difference in how men and women experience the impact of TBI although there may not be a clear divide in objective outcome measures (Schopp, Shigaki, Johnstone \& Kirkpatrick, 2001). Howes, Benton and Edwards, (2005) researched women's experiences of TBI, and findings support themes within broader TBI literature in relation to adjustment and changes in identity. However, although the research enables some exploration of this experience, specifically for women through selective recruitment, the study does not appear to specifically ask or explore women's experiences in relation to their identity as a woman. Further research specifically focusing on this may help to inform assessment, formulation and intervention following TBI.

\section{Clinical Implications and Conclusions}

This research offers an in-depth exploration and understanding of men's experiences of TBI in relation to their identity as a man. The findings suggest that identity as a man was challenged when ideals about independence, agency and roles within relationships were difficult to maintain. Clinicians should therefore consider the relational context of identity using assessments which explore social relationships. For example, discussing roles and values and how these are expressed in behaviour, may support couples in adapting to any changes in roles and responsibilities they may face as they renegotiate their relationships (Douglas \& Bracy, 2013).

Services may promote engagement in rehabilitation by adapting approaches to assessment and intervention. Providing a gender-sensitive service can begin during initial 
discussions when men are referred to a service. Emphasising an active and expert role rather than being a passive recipient in rehabilitation may particularly promote a service which is in line with masculine ideals. Providing opportunities for exploring new activities which are in line with a person's values as a man or considering ways to adapt activities may be relevant. Sullivan, Gray, Williams, Green, and Hession (2014) explore the use of real life activities such as shopping, cooking, woodwork, sports and fishing within assessment and interventions. The findings gathered from interviews from the young men in Australia suggested that the use of meaningful activities in this way promoted engagement. Similarly, encouraging active roles with professionals and in the community may enable a sense of meaningful and valued contribution, which can promote a positive sense of masculine identity.

The findings of the current study suggest that drawing on masculine ideals such as resilience and strength may be helpful in adjusting to the impact of TBI. Given the experiences of reformulation and growth identified by participants, recovery-based approaches which focus on narratives and values may be particularly relevant within rehabilitation. Acceptance and Commitment Therapy, as well as approaches which promote growth and target shame and stigma such as the compassionate mind approach (Gilbert, 2007), may enable the exploration of new ways of expressing their identity as a man. Clinicians working with men following TBI could validate the experience of shame in relation to the discrepancies between masculine ideals and use this to the negative impact of TBI on mental health. Aspects of positive psychotherapy which focuses on domains such as growth, character strengths and resilience (Rashid \& Seligman, 2013) have been explored in inpatient settings (Andrewes, Walker, \& O’Neill, 2014) as well as outpatient settings (Cullen et al., 2016) following TBI and are also supported in the current study. 
In conclusion, rehabilitation can help individuals to make sense of their experiences of discrepancies in identity and to consider adapting activity in order to have meaningful experiences in line with identity and values. Working with men to explore the values which are meaningful to them as individuals, particularly in relation to masculine identity, may enable men to explore new ways of expressing their identity as a man as they adjust to the consequences of a TBI.

\section{Acknowledgements}

The authors would like to thank all the participants who took the time to take part in this research and share their personal experiences. The support of the clinicians who reviewed their caseloads and recruited participants is also gratefully acknowledged.

\section{References}

Addis, M. E., \& Mahalik, J. R. (2003). Men, masculinity, and the contexts of help seeking. The American Psychologist, 58(1), 5-14. https://doi.org/10.1037/0003-066X.58.1.5

Andrewes, H. E., Walker, V., \& O’Neill, B. (2014). Exploring the use of positive psychology interventions in brain injury survivors with challenging behaviour. Brain injury, 28(7), 965-971.

Biggerstaff, D., \& Thompson, A. R. (2008). Interpretative Phenomenological Analysis (IPA): A Qualitative Methodology of Choice in Healthcare Research. Qualitative Research in Psychology, 5(3), 214-224. https://doi.org/10.1080/14780880802314304

Courtenay, W.H., (2000) Constructions of masculinity and their influence on men's wellbeing: A theory of gender and health. Social Science and Medicine, 50 (10), 13851401. doi:10.1016/S0277-9536(99)00390-1

Cullen, B., Pownall, J., Cummings, J., Baylan, S., Broomfield, N., Haig, C., ... \& Evans, J. J. (2016). Positive PsychoTherapy in ABI Rehab (PoPsTAR): A pilot randomised controlled trial. Neuropsychological Rehabilitation, 1-17.

doi:10.1080/09602011.2015.1131722 
Douglas, J. M., \& Bracy, C. A. (2013). Coping efforts used by couples living with severe traumatic brain injury: A comparison with orthopaedic control couples. Brain Impairment, 14(1).

Conway, M. A., \& Pleydell-Pearce, C. W. (2000). The construction of autobiographical memories in the self-memory system. Psychological review, 107(2), 261.

Freeman, A., Adams, M., \& Ashworth, F. (2014). An exploration of the experience of self in the social world for men following traumatic brain injury. Neuropsychological Rehabilitation, (July), 1-27. https://doi.org/10.1080/09602011.2014.917686

Galdas, P. M., Cheater, F., \& Marshall, P. (2005). Men and health help-seeking behaviour: Literature review. Journal of Advanced Nursing, 49(6), 616-623.

Gerschick, T. J. (2000). Toward a Theory of Disability and Gender, 25(4), 1263-1268.

Gilbert, P. (2007). Evolved minds and compassion in the therapeutic relationship. In Gilbert, P. \& Leary, R. (Eds) The therapeutic relationship in the cognitive behavioural psychotherapies (pp.106-142). London: Routledge

Good, G. E., Schopp, L. H., Thomson, D., Hathaway, S., Sanford-Martens, T., Mazurek, M. O., \& Mintz, L. B. (2006). Masculine roles and rehabilitation outcomes among men recovering from serious injuries. Psychology of Men \& Masculinity, 7(3), 165.

Gutman, S. A., \& Napier-Klemic, J. (1996). The experience of head injury on the impairment of gender identity and gender role. American Journal of Occupational Therapy, 50(7), 535-544. doi:10.5014/ajot.50.7.535

Haslam, C., Holme, A., Haslam, S.A., Iyer, A., Jetten, J., \& Williams, W.H. (2008). Maintaining group memberships: Social identity continuity predicts well-being after stroke. Neuropsychological Rehabilitation, 18(5-6), 671-691.

Headway (2014), Key Facts and Statistics Retrieved from https://www.headway.org.uk/keyfacts-and-statistics.aspx accessed 28.08.2015

Hollis, S. J., Stevenson, M. R., McIntosh, A. S., Shores, E. A., Collins, M. W., \& Taylor, C. B. (2009). Incidence, risk, and protective factors of mild traumatic brain injury in a cohort of Australian nonprofessional male rugby players. The American Journal of Sports Medicine, 37(12), 2328-2333. 
Hutchinson, S. L., \& Kleiber, D. A. (2000). Heroic masculinity following spinal cord injury: Implications for therapeutic recreation practice and research. Therapeutic Recreation Journal, 34(1), 42.

Javouhey, E., Guerin, A. C., \& Chiron, M. (2006). Incidence and risk factors of severe traumatic brain injury resulting from road accidents: a population-based study. Accident Analysis \& Prevention, 38(2), 225-233. https://doi.org/10.1016/j.aap.2005.08.001

Jetten, J., Haslam, C., \& Alexander, S. H. (Eds.). (2012). The social cure: Identity, health and well-being. Psychology Press.

Jones, J. A., \& Curtin, M. (2011). Reformulating masculinity: traumatic brain injury and the gendered nature of care and domestic roles. Disability and Rehabilitation, 33(1718), 1568-1578.

Kangas, M., \& McDonald, S. (2011). Is it time to act? The potential of acceptance and commitment therapy for psychological problems following acquired brain injury. Neuropsychological Rehabilitation, 21(2), 250-276.

Kingerlee, R. (2012). Conceptualizing men: A transdiagnostic model of male distress. Psychology and Psychotherapy: Theory, Research and Practice, 85(1), 83-99. doi:10.1111/j.2044-8341.2011.02017.x

Larkin, M., Watts, S., \& Clifton, E. (2006). Giving voice and making sense in interpretative phenomenological analysis. Qualitative Research in Psychology, 3(2), 102-120. https://doi.org/10.1191/1478088706qp062oa

Lennon, A., Bramham, J., Carroll, I., Mcelligott, J., Carton, S., Waldron, B., ... Benson, C. (2014). A qualitative exploration of how individuals reconstruct their sense of self following acquired brain injury in comparison with spinal cord injury. Brain Inj, 28(1), 1362-301. https://doi.org/10.3109/02699052.2013.848378

LeDoux, J. E. (2000). Emotion circuits in the brain. Annual review of neuroscience, 23(1), 155-184.

Meyers, N. M. (2012). The effect of traditional masculine gender role adherence on community reintegration following traumatic brain injury in military veterans. (Doctoral Thesis) American University, Washington, D.C

Morriss, E., Wright, S., Smith, S., Roser, J., \& Kendall, M. (2013). Parenting challenges and 
needs for fathers following acquired brain injury (ABI) in Queensland, Australia: A preliminary model. Special Issue: Family Support and Adjustment Following Acquired Brain Injury: An International Perspective., 19(2), 119-134. https://doi.org/10.1017/jrc.2013.15

Muenchberger, H., Kendall, E., \& Neal, R. (2008). Identity transition following traumatic brain injury: a dynamic process of contraction, expansion and tentative balance. Brain Injury : [BI], 22(12), 979-992. https://doi.org/10.1080/02699050802530532

Nochi, M. (1998). "Loss of self" in the narratives of people with traumatic brain injuries: A qualitative analysis. Social Science and Medicine, 46(7), 869-878.

Rashid, T., \& Seligman, M. (2013). Positive Psychotherapy. In Wedding \& Corsini (Eds.) Current Psychotherapies, (pp 461- 494). Belmont: Cengage Learning.

Robertson, S., Sheikh, K., \& Moore, a. (2010). Embodied masculinities in the context of cardiac rehabilitation. Sociol Health Illn, 32(5), 695-710. https://doi.org/10.1111/j.1467-9566.2010.01249.x

Rodham, K., Fox, F., \& Doran, N. (2013). Exploring analytical trustworthiness and the process of reaching consensus in interpretative phenomenological analysis: lost in transcription. International Journal of Social Research Methodology, (June 2014), 113. https://doi.org/10.1080/13645579.2013.852368

Roe, D., Hasson-Ohayon, I., Mashiach-Eizenberg, M., Derhy, O., Lysaker, P. H., \& Yanos, P. T. (2014). Narrative enhancement and cognitive therapy (NECT) effectiveness: A quasi-experimental study. Journal of Clinical Psychology, 70(4), 303-312.

Shakespeare, T. (1999). The sexual politics of disabled masculinity. Sexuality and disability, $17(1), 53-64$.

Schopp, L. H., Shigaki, C. L., Johnstone, B., \& Kirkpatrick, H. a. (2001). Gender Differences in Cognitive and Emotional Adjustment to Traumatic Brain Injury. Journal of Clinical Psychology in Medical Settings, 8(3), 181-188. https://doi.org/10.1023/a:1011369620254

Shinebourne, P. (2011). The theoretical underpinnings of interpretative phenomenological analysis ( IPA ). Existential Analysis, 22(January), 16-31. 
Smith, J. A. (1996). Beyond the divide between cognition and discourse: Using interpretative phenomenological analysis in health psychology. Psychology and Health, 11(2), 261-271.

Smith, J. A., Flowers, P., \& Larkin, M. (2009). Interpretative phenomenological analysis: Theory, method and research. London, England: Sage.

Smith, J. (2011). Evaluating the contribution of interpretative phenomenological analysis. Health Psychology Review, 5(1), 9-27. https://doi.org/10.1080/17437199.2010.510659

Sullivan, C., Gray, M., Williams, G., Green, D., \& Hession, C. (2014). The use of real life activities in rehabilitation: The experience of young men with traumatic brain injuries from regional, rural and remote areas in Australia. Journal of Rehabilitation Medicine, 46(5), 424-429. https://doi.org/10.2340/16501977-1788

Tajfel, H., \& Turner, J. C. (1979). An integrative theory of intergroup conflict. The social psychology of intergroup relations, 33(47), 74.

Thomas, E. J., Levack, W. M. M., \& Taylor, W. J. (2014). Self-Reflective Meaning Making in Troubled Times: Change in Self-Identity After Traumatic Brain Injury. Qualitative Health Research, 24(8), 1033-1047. https://doi.org/10.1177/1049732314542809

Tong, A., Sainsbury, P., \& Craig, J. (2007). Consolidated criteria for reporting qualitative research (COREQ): a 32-item checklist for interviews and focus groups. International Journal for Quality in Health Care, 19(6), 349-357. doi: 10.1093/intqhc/mzm042

Tyerman, A. (2009) Facilitating Psychological Adjustment. In Psychological approaches to rehabilitation after traumatic brain injury (eds A. Tyerman and N. S. King), Oxford, UK: BPS Blackwell.

Wilson, N. J., Shuttleworth, R., Stancliffe, R., \& Parmenter, T. (2012). Masculinity Theory in Applied Research with Men and Boys with Intellectual Disability. Intellectual and Developmental Disabilities, 50(3), 261-272. https://doi.org/10.1352/1934-955650.3 .261 
Wise, E. K., Hoffman, J. M., Powell, J. M., Bombardier, C. H., \& Bell, K. R. (2012). Benefits of exercise maintenance after traumatic brain injury. Archives of Physical Medicine and Rehabilitation, 93(8), 1319-1323. doi:10.1016/j.apmr.2012.05.009

Yardley, L. (2008). Demonstrating validity in qualitative psychology. Qualitative Psychology: A Practical Guide to Research Methods, 2, 235-251.

Yeates, G. N., Gracey, F., \& Mcgrath, J. C. (2008). A biopsychosocial deconstruction of "personality change" following acquired brain injury. Neuropsychological Rehabilitation, 18(5-6), 566-589. https://doi.org/10.1080/09602010802151532 


\section{Appendices}

Table 1

Contextual information about participants

\begin{tabular}{|c|c|c|c|c|c|c|}
\hline Name & $\begin{array}{l}\text { Age group } \\
\text { (years) }\end{array}$ & Time since injury & Cause of injury & Lives with: & Post injury employment & education \\
\hline John & $30-40$ & 6 years & Pedestrian in RTC & Wife $\& 2$ children & No & Completed high school at age 16. \\
\hline Luke & $20-30$ & 2 years & RTC & Alone & No & Completed high school at age 18. \\
\hline Gordon & $40-50$ & 3 years & RTC & Parents & No & $\begin{array}{l}\text { Completed high school at age } 16 \& \text { did } \\
\text { further vocational qualifications. }\end{array}$ \\
\hline Jake & $20-30$ & 1 year & Physical altercation & Girlfriend & No & $\begin{array}{l}\text { Completed high school at age } 16 \& \text { did } \\
\text { qualification In car mechanics. }\end{array}$ \\
\hline Simon & $30-40$ & $41 / 2$ years & Motorbike RTC & Wife \& 2 children & No & Completed high school at age 16. \\
\hline Nigel & $40-50$ & 1 year & Bicycle RTC & Wife $\& 3$ children & $\begin{array}{l}\text { Has begun to return to } \\
\text { different role in same } \\
\text { place }\end{array}$ & Completed high school at age 16. \\
\hline Chris & $20-30$ & 2 years & Driver in road traffic collision & Alone & $\begin{array}{l}\text { Has returned to work in } \\
\text { same role }\end{array}$ & Completed high school at age 18. \\
\hline Smith & $60-70$ & 3 months & Fall & Wife & Retired & $\begin{array}{l}\text { Completed high school at age } 15 \& \text { joined } \\
\text { the military }\end{array}$ \\
\hline Peter & $20-30$ & 6 months & Single car accident & Parents & No & $\begin{array}{l}\text { Completed high school at age } 18 . \\
\text { Completed national diploma. }\end{array}$ \\
\hline George & $40-50$ & 11 months & Accident at work with machinery & Partner \& 3 children & $\begin{array}{l}\text { Returned part time to } \\
\text { same but altered duties } \\
\text { role }\end{array}$ & Completed high school at age 16. \\
\hline
\end{tabular}


Figure 1. Summary of Superordinate Themes and Master Themes.

\begin{tabular}{|c|c|c|}
\hline $\begin{array}{l}\text { Doing life and } \\
\text { relationships } \\
\text { differently }\end{array}$ & $\begin{array}{l}\text { Self-perceptions and the perceived } \\
\text { view of others }\end{array}$ & $\begin{array}{l}\text { Managing the Impact of } \\
\text { TBI as a man }\end{array}$ \\
\hline $\begin{array}{ll}\text { - } & \text { Loss of } \\
\text { individual } \\
\text { agency and } \\
\text { independence }\end{array}$ & $\begin{array}{l}\text { The invisible nature of the } \\
\text { injury as both protective and } \\
\text { threatening to masculine } \\
\text { identity. } \\
\text { - Concern about being judged } \\
\text { as less of a man } \\
\text { - Shame and loss of self- } \\
\text { confidence } \\
\text { - Not feeling safe, feeling } \\
\text { vulnerable }\end{array}$ & $\begin{array}{l}\text { - Coping with } \\
\text { adjustments } \\
\text { - Re-evaluating life/ } \\
\text { values }\end{array}$ \\
\hline
\end{tabular}




\section{Interview Topic Guide}

The participant will be orientated to the area of research through use of the participant information sheet. Before the interview begins the key aims of the study will again be explained. The following will be outlined although is not a rigid script: "This research is about finding out what it is like to live with a traumatic brain injury as a man. I am interested in finding out about your individual life experiences in relation to your identity as a man and there are no right or wrong answers. l'd like to hear about the kinds of things that are important for you and at times I might ask you to expand on what you've said or give examples, as long as you feel comfortable to do so. Firstly, I have a few questions to find out a bit about you and then we'll move on to talking more about what is like for you as a man to have a traumatic brain injury."

\section{Background Information}

- Current Age:

- Who lives at home with you?

- Educational background: what age did you leave school? Do you have any years of further education?

- Employment: If you were employed before your injury what did you do? Are you currently employed? What do you do?

- What age were you when you had the injury?

- Can you tell me about how you came to have a traumatic brain injury?

- Following your injury did you have an inpatient stay in an acute and/or specialist hospital? What was the duration of your stay?

- Are you currently receiving any support from professionals? (duration, type of therapy?)

So now l've asked a few questions to find out a bit more about you, l'd like to ask move on to talking more about what is like for you as a man to have a traumatic brain injury."

\section{Questions about masculine identity:}

- For you, as a man, what is it like to live with your brain injury on a day-to-day basis? (prompts: day-to-day activities, how you fill your day, interactions with others)

- Can you tell me about any times when you particularly felt TBI impacted your identity as a man?

- Since having a TBI, are there any changes in what it is like for you to be a man? Prompts: are there any differences for you, as a man, between before and after your injury? 
- Since having a TBI, can you tell me about what it is like doing things which you feel are part of your role, as a man?

- As a man, what is it like to come for appointments and meet with health professional's here/hospital/ rehabilitation clinicians?

Prompts: clinicians involved e.g. physio/OT, attending appointments, meetings with professionals.

- I've been asking lots of questions so far, but is there anything else you wanted to say about what it's like for you as a man to experience a brain injury

- What has it been like talking to me today about your experiences? Prompts: to encourage reflection on interview process. Debrief procedure to be followed.

Further questioning using prompts will be used throughout. For example, "can you give me an example of that?" "Can you tell me more about that?" "Can you describe that in more detail to me" "How did that feel at that particular moment?" 